\title{
LA INFORMALIDAD EN LOS SECTORES ECONÓMICOS Y LA EVASIÓN TRIBUTARIA EN EL PERÚ
}

Elsa E. Choy Zevallos*

Docente Asociada de la Facultad de Ciencias Contables - UNMSM

\section{EDUARDO ALBERTO MONTES FARRO**}

Docente Asociado de la Facultad de Ciencias Contables, UNMSM

[Recepción: Febrero de 2011/ Conformidad: Abril de 2011]

\section{RESUMEN}

El Perú es uno de los países de Latinoamérica que presenta mayores índices de informalidad empresarial lo cual conlleva a un alto grado de evasión tributaria. La actividad económica en condiciones de informalidad que existe en nuestro país se le atribuye, entre sus principales causas, el costo de la legalidad, las restricciones legales y actividades de fiscalización establecida por ley.

El tema es importante porque pretende señalar la relación que existe entre la economía informal y la evasión tributaria, las cuales se enumeran, clasifican e informa aspectos relacionados con la realidad nacional. Desarrolla un marco teórico de los sectores económicos, la informalidad y evasión tributaria, analiza causas y consecuencias y por último presenta las conclusiones y recomendaciones con la finalidad de mejorar la recaudación tributaria en nuestro país.

Palabras Claves: Sectores Económicos, Informalidad, Evasión Tributaria.

\begin{abstract}
Peru is one of the Latin American countries that have higher rates of business informality which leads to a high degree of tax evasion. The activity in the informal economy that exists in our country is attributed, among its main causes, the cost of legality, legal restrictions and control activities established by law.

The issue is important because it seeks to identify the relationship between the informal economy and tax evasion, which are listed, classified and reported issues related to national reality. Develop a framework of economic sectors, informality and tax evasion, discusses causes and consequences, and finally presents the conclusions and recommendations in order to improve tax collection in our country.
\end{abstract}

Key words: Economic Sectors, Informality, Tax Evasion

\footnotetext{
* Doctora en Ciencias Contables y Empresariales. Magister en contabilidad, UNMSM. Contadora Pública Colegiada Certificada. Docente Investigadora de la Facultad de Ciencias Contables, UNMSM.

E-mail: eschoyz@yahoo.com

** Egresado de Maestría en mención en Costos, UNMSM. Contador Público Colegiado Certificado, Docente Investigador de la Facultad de Ciencias Contables, UNMSM.

E-mail: amontesfa1@yahoo.es
} 


\section{INTRODUCCIÓN}

El tema La Informalidad en los Sectores Económicos y la Evasión Tributaria en el Perú, es importante porque tiene su impacto en el desarrollo de las empresas y por ende en el crecimiento económico de nuestro país.

La informalidad en el Perú data de muchos años, se acentúa con la presencia del comercio ambulatorio, es decir, negocios que no se encuentran registrados ante la Administración Tributaria, según lo establece la ley como requisito para que formalmente sean controlados y supervisados como sujetos pasivos de la relación jurídica tributaria.

Asimismo, la evasión tributaria que presenta este sector es latente, a causa de este fenómeno conlleva múltiples efectos negativos en la economía nacional y desarrollo social de nuestro país.

El tema desarrolla un marco teórico sustentado principalmente por fuentes bibliográficas como la de Hernando De Soto y el Instituto Libertad y Democracia en el Perú, quienes desarrollaron una serie de investigaciones en cuatro sectores de la empresa informal, la industria, el alojamiento, el comercio y el transporte. Basados en estas investigaciones se puede entender porque la mayor parte de peruanos actúan al margen de la legalidad

En cuanto a la magnitud del sector informal se establece por aproximaciones, ya que no aparece en las estadísticas oficiales de las Cuentas Nacionales, por lo que se desconoce con exactitud su medición e incidencia en la economía nacional; lo que constituye una gran limitación al estudio. Finalmente presentamos las conclusiones y recomendaciones al tema desarrollado.

\section{LA INFORMALIDAD EN LOS SECTO- RES ECONÓMICOS}

El sector informal se define como el conjunto de unidades económicas que no cum- plen con todas las regulaciones e impuestos. Más aun, las actividades informales emplean medios ilegales para satisfacer objetivos esencialmente legales. No son informales los individuos sino sus actividades, al punto que un agente económico puede participar de manera formal en un mercado pero de modo informal en otro. En la mayoría de los casos las unidades económicas desobedecen disposiciones legales precisas.

\section{- El comercio informal}

El comercio es la rama de actividad informal que más trabajadores ocupa, ,es considerado a su vez como una actividad refugio, donde llegan los trabajadores de otras ramas. En este sector se encuentran numerosos comercios abiertos contiguos a otras viviendas en los barrios populares, dedicados a las ventas de alimentos, bazares, prendas de vestir, comidas.

El comercio informal se lleva a cabo fundamentalmente a través del comercio en la calle, los llamados vendedores ambulantes, que existen en todo el país. La mayoría de origen humilde, provincianos migrantes del campo a la ciudad. Elúltimo censo señala aproximadamente 300,000 vendedores ambulantes en Lima.

\section{- La industria informal}

La industria informal se caracteriza por la precariedad tecnológica con que opera esta rama de actividad, solo puede acceder a la producción de aquellos bienes que requieren procesos de producción simples e intensivos en trabajo, son esencialmente actividades como: confeccionistas de prendas de vestir, carpinteros, preparación de alimentos, talleres de pequeñas imprentas, zapateros, joyeros, talleres de productos metálicos.

En el Perú la presencia de la informalidad en la industria es significativa. Presenta 
dos tipos, uno es el propio industrial formal que informaliza parte de su producción como consecuencia del alto costo de la regulación o de los impuestos, otro tipo de informales en el sector industrial son los artesanos o los industriales propiamente informales, que se dedican de una manera completamente ilegal al desarrollo de alguna actividad manufacturera.

\section{- Los servicios informales}

El más notable de los servicios informales es el transporte. En los países desarrollados, el transporte público es generalmente estatal; en los países en desarrollo, el transporte público es generalmente privado e informal.

\section{CAUSAS DE LA INFORMALIDAD}

Algunos fenómenos de la expansión del sector informal fueron:

- El alto costo de la legalidad

- Actividades de fiscalización establecida por ley.

- La pobreza es uno de los factores del crecimiento de la economía informal

- La crisis financiera asiática provocó un crecimiento acelerado de las actividades económicas marginales.

- La migración de personas provenientes de zonas rurales a la Ciudad

- La tecnología demanda personal altamente especializada y relega a las personas no cualificadas que buscan trabajo en el sector informal

- Los salarios del sector público son insuficientes

\section{LA EVASIÓN TRIBUTARIA}

El término evasión, significa toda actividad racional dirigida a sustraer, total o parcialmente, en provecho propio, un tributo legalmente debido al Estado. El término eva- sión fiscal o tributaria, es toda eliminación o disminución de un monto tributario producido dentro del ámbito de un país por parte de quienes están jurídicamente obligados a abonarlo y que logran tal resultado mediante conductas fraudulentas u omisas violatorias de disposiciones legales.

En resumen en este concepto conjugan varios elementos, donde uno de los más importantes es que existe una eliminación o disminución de un tributo y donde además se trasgrede una ley de un país, por los sujetos legalmente obligados.

La evasión fiscal en el Perú se encuentra por encima de los estándares internacionales de países con características económicas y sociales similares. El índice de incumplimiento del IGV e Impuesto a la Renta, viene registrando una tendencia negativa en los últimos años, los niveles son relativamente elevados comparado con otros países, lo cual demanda un mayor énfasis en el empleo de mecanismos de control, la utilización de tecnología de última generación, así como disponer de una gran base de información interinstitucional y contar con recurso humano altamente especializado.

\section{CAUSAS DE EVASIÓN TRIBUTARIA}

Entre las principales causas tenemos:

- Carencia de una conciencia tributaria

- Sistema tributario poco transparente

- Administración tributaria poco flexible

- Bajo riesgo de ser detectad

\section{LA BRECHA DEL INCUMPLIMIENTO}

Las principales obligaciones del contribuyente son: inscripción, presentación de declaración, veracidad y pago del impuesto. De allí surgen las brechas del incumplimiento:

- Contribuyentes que teniendo la obligación de inscribirse no lo hacen. 
- Inscriptos que han declarado pero que no pagan.

- Contribuyentes que declaran incorrectamente.

Debe tenerse en cuenta que para mejorar la recaudación es cerrar las brechas de incumplimiento. En muchos casos se trata de personas que incumplen porque no están inscritos en la Administración Tributaria, y se sitúan como informales.

Las Brechas de Incumplimiento

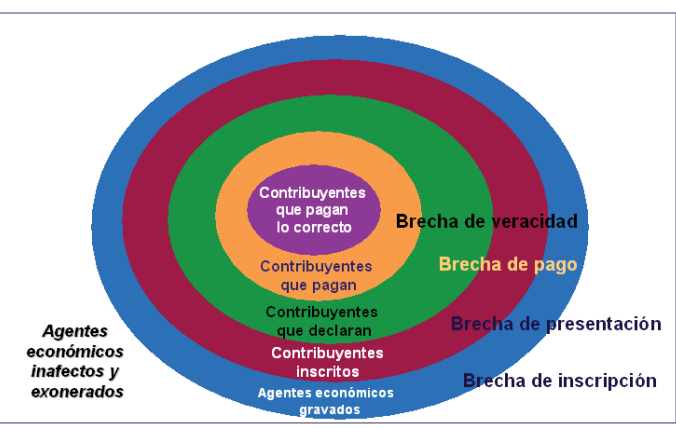

\section{EL SECTOR INFORMAL Y LA EVA- SIÓN TRIBUTARIA EN EL PERÚ}

La economía informal y la evasión tributaría se relacionan recíprocamente tanto en sus causas como en sus efectos.

Hernando de Soto en su obra el Otro Sendero señala:

$\ll$ El incumplimiento de las obligaciones directas y las leyes laborales es una de las diferencias, entre formales e informales; los empresarios formales pagan sus impuestos y lo hacen por ellos y por los que no pagan; los empresarios informales que evaden sus obligaciones tributarias producen como efecto que la carga tributaria se haga más pesada para aquellos que cumplen con sus impuestos».

El alto índice de informalidad empresarial que atraviesa nuestro país conlleva a un alto grado de evasión tributaria, ante esta situación, el Estado a través de la Administración Tributaria ha creado regímenes de pago adelantado del Impuesto General a las Ventas y recientemente bajar la tasa de $19 \%$ a $18 \%$, a fin de asegurar la recaudación de impuestos, ampliar la base tributaria y evitar la evasión que se produce principalmente en la comercialización, cuya cadena de distribución presenta mayores índices de informalidad.

Tratándose del impuesto a la renta, un reciente estudio elaborado para la CEPAL por Luis Alberto Arias, ex Jefe de la SUNAT muestra que la evasión tributaria en el 2006 del impuesto a la renta de personas naturales fue $32.6 \%$ y de empresas $51.3 \%$. Es indudable que estos altos niveles de evasión tributaria constituyen uno de los problemas centrales en nuestro país, que debe encarar una verdadera reforma tributaria integral.

\section{CONCLUSIONES}

1. El sector informal, asociado al comercio ambulatorio y actividades de producción no registradas oficialmente, origina implicancias negativas para el crecimiento económico de un país, siendo causa de la reducción de la base impositiva y evasión tributaria.

2. El comercio informal integrado por comerciantes que no están registrados ante la Superintendencia de la Administración Tributaria (SUNAT), afecta al Sistema Tributario a consecuencia de la evasión del impuesto general a las ventas, que se produce cuando perciben el monto de los impuestos contenidos en el valor de las mercaderías, pero no trasladan a las cajas de la Administración Tributaria, porque no son sujetos de la obligación formal.

3. La industria informal integrada por el industrial que se dedican de una manera completamente ilegal al desarrollo de alguna actividad manufacturera y no registra oficialmente sus ingresos, ni los decla- 
ra, afecta la recaudación del impuesto a la renta en nuestro país, porque no traslada a la caja fiscal de la Administración Tributaria por no estar identificados como sujetos de obligación formal.

\section{RECOMENDACIONES}

1. El Estado debería implementar un sistema impositivo más sencillo, con la finalidad que el micro comerciante e industrial que aún se encuentra en la informalidad pase a ser formal, esto sumado a una adecuada política de comunicación y asistencia, permitirá mejorar el cumplimiento de las obligaciones y generar mayores recursos fiscales para la creación de infraestructura y mejoramiento de los servicios públicos.

2. La Administración Tributaria debe contemplar seguir reduciendo la tasa del $18 \%$ del impuesto general a las ventas, con la finalidad de bajar los altos índices de evasión en el comercio informal.
3. La Administración Tributaria debe contemplar un sistema de declaración de ingresos que no perjudique la economía del micro y pequeño industrial, creando una tasa de impuesto a la renta más justa y que responda al cumplimiento voluntario del industrial informal.

\section{REFERENCIAS BIBLIOGRÁFICAS}

1. De Soto, Hernando (1994). El otro sendero. La revolución informal en el tercer mundo. Ediciones La Découverte, Paris.

2. De Soto, Hernando (1994). La economía informal futuro del tercer mundo? Revista Alternativas Económicas $N^{\circ} 122$, Paris.

3. DURÁN ROJO, Luís (2005): "La informalidad tributaria”. diario El Peruano, Perú.

4. Gestión en el Tercer Milenio (2005), Revista de Investigación de la Facultad de Ciencias Administrativas, UNMSM, Vol. 7, N. ${ }^{\circ}$ 14, Lima. 